\title{
PRODUÇÃO DE EXOPOLISSACARÍDEOS A PARTIR DE BASTONETES GRAM- POSITIVOS ISOLADOS DE CONTAMINANTES DE CULTURA DE TECIDO VEGETAL
}

Raylane Pereira Gomes ${ }^{1}$; Renan de Souza Soares ${ }^{2}$; Bruno Francesco Rodrigues de Oliveira $^{3}$; Thaís Maitan Vieira ${ }^{2}$; José Daniel Gonçalves Vieira ${ }^{4}$

1 Mestranda em Biologia da Relação Parasito-Hospedeiro, Universidade Federal de Goiás (raylanepgomes@gmail.com)

2 Mestre em Ciências Ambientais, Universidade Federal de Goiás

3 Professor Mestre do Departamento de Bioquímica e Biologia Molecular do Instituto de Ciências Biológicas da Universidade Federal de Goiás

4 Professor Doutor do Instituto de Patologia Tropical e Saúde Pública da

Universidade Federal de Goiás, Goiânia-Brasil

Recebido em: 03/10/2016 - Aprovado em: 21/11/2016 - Publicado em: 05/12/2016

DOI: 10.18677/EnciBio 2016B 122

Contaminantes presentes nas culturas de tecido vegetal comumente estão associados a micro-organismos endofíticos. Estes micro-organismos geralmente apresentam uma produção de algum biocompostos, que podem ser utilizados como produtos biotecnológicos, entre eles, os exopolissacarídeos (EPSs). Um vasto número de bactérias conhecidas produz quantidade significativa de EPSs, chamando a atenção nas últimas décadas tanto da pesquisa como da indústria, devido às suas propriedades e aplicações. A produção de EPSs por microorganismos é uma alternativa de uma nova fonte de produção de polímeros solúveis ou insolúveis que possuem uma vasta aplicação nas áreas ambientais, medicina e nas indústrias alimentícias, química e farmacêutica. EPSs são produtos do metabolismo celular dos micro-organismos onde podem estar ligados a superfície da célula ou quando são excretados para o meio. Para tanto, objetivou-se neste estudo verificar a produção de EPSs por bastonetes gram-positivos. Seis cepas foram utilizadas para a produção de EPSs em meio de cultivo direcionado para formação do polímero celulose. Todas as cepas utilizadas produziram quantidade significativa de EPSs, tendo sua maior produção no tempo de 48 horas, sendo selecionadas duas cepas com maiores produções de EPSs. Foi relacionada uma associação positiva de densidade bacteriana com a produção de biomassa de EPSs. Com a microscopia eletrônica de varredura (MEV) foi possível visualizar a produção dos EPSs. Em conclusão, os resultados demonstram o potencial das cepas bacterianas em produzir EPSs, sendo necessário novos estudos, para sua caracterização e potencial aplicação.

PALAVRAS-CHAVE: biocompostos, celulose, endofíticos. 


\title{
PRODUCTION OF EXOPOLYSACCHARIDES FROM GRAM-POSITIVE ISOLATED RODS FROM CONTAMINANTS IN THE CULTIVATION OF PLANT TISSUE
}

\begin{abstract}
Contaminants present in the cultures of plant tissue commonly are associated with endophytic microorganisms. These microorganisms usually have a production of some biological compounds which can be used as biotechnological products, among them, the exopolysaccharides (EPSs). A vast number of bacteria known produces significant amount of EPSs, drawing attention in recent decades both in the research and industry, due to its properties and applications. The production of EPSs by microorganisms is an alternative to a new source of production of soluble or insoluble polymers, that have a wide application in environmental areas and medicine, food chemical and pharmaceutical industries. EPSs are products of cellular metabolism of microorganisms that can be connected to the cell surface or when they are excreted to the medium. For this reason, the goal of this work was to verify the production of EPSs by gram-positive rods bacteria. Six strains were used for the production of EPSs in culture medium directed to the formation of the polymer cellulose. All of the used strains have produced significant amount of EPSs, having its higher production during the first 48 hours, being selected two strains with higher yields of EPSs. A positive association of bacterial density was linked to the production of biomass of EPSs. With the scanning electron microscopy (SEM) was able to see the production of EPSs. In conclusion, the results demonstrate the potential of bacterial strains to produce EPSs, being necessary new studies related to their characterization and potential application.
\end{abstract}

KEYWORDS: Biological Compounds, Cellulose, Endophytes.

\section{INTRODUÇÃO}

Micro-organismos capazes de habitar a região interna de tecidos vegetais sem promover efeitos negativos evidentes, denominados micro-organismos endofíticos, são uma fonte inestimável de produtos bioativos. Deste grupo bacteriano já foram caracterizados biocompostos antibióticos, antivirais, agentes antidiabéticos, antioxidantes, dentre outros (LIU et al. 2009). Em ensaios de micropropagação vegetal, os endofíticos vêm sendo mencionados em vários estudos como fontes de contaminação, porém, outros consideram sua presença como um fator positivo capaz de auxiliar a planta uma vez que vivem no interior de seus tecidos sem causar doenças sintomáticas devido a sua presença. Podendo no caso específico do cultivo in vitro, favorecer o ajuste osmótico, a produção de fitormônios e absorção de nutrientes (POLESI, 2011).

Micro-organismos endofíticos a e planta hospedeira estabelecem uma relação ecológica de simbiose e/ou mutualística harmônica em que o endófito consegue nutrição e proteção, em contrapartida do vegetal adquirir proteção contra fitopatógenos, herbívoros e insetos e indução de crescimento (ORLANDELLI et al., 2016). Essa relação entre planta hospedeira com a comunidade endofítica envolve um processo de coevolução regido pela sua colonização, que é influenciada pelo genótipo microbiano e vegetal, e diferentes fatores inerentes ao vegetal tais como estágio de crescimento da planta, status fisiológico, tipo de tecido vegetal, prática agrícola utilizada, além de condições ambientais (POLESI, 2011).

Exopolissacarídeos (EPSs) são polímeros biossintetizados e secretados por micro-organismos. A produção pode estar relacionada ao metabolismo natural de bactérias, cianobactérias, organismos do filo Cryptophyta, cogumelos e leveduras 
(SINGH et al., 2011). A produção microbiana de EPS tem sido largamente estudada devido a extensa aplicação do bioproduto na indústria, principalmente a atividade médica-farmacêutica para estabilização de agentes, produção de imunoestimulantes, antitumorais e cosméticos (LIU et al., 2012 MAHAPATRA \& BANERLEE, 2012; ARUN et al., 2017).

Apesar de constituído majoritariamente por carboidratos, EPSs são formados por diferentes biomoléculas, como proteínas, ácidos nucleicos, fosfolipídeos e vários compostos orgânicos de distintos grupos funcionais, além de constituintes inorgânicos (SINGH et al., 2011). A combinação única de suas estruturas químicas é a responsável pelo desemprenho funcional de proteção da célula microbiana contra dissecação, bacteriófagos, estresse osmótico e ação de anticorpos. Os EPSs podem ser diferenciados pela forma de ocorrência na célula microbiana, que varia do capsular (polímero associado a célula microbiana) ou polissacarídeo viscoso (fracamente associado a célula microbiana) (CASTELLANE et al., 2014; SARDARI et al., 2017).

Micro-organismos endofíticos são descritos na literatura como produtores de EPSs, como Paenibacillus polymyxa, Hypocreales sp, Mesorhizobium loti e Bacillus amyloliquefaciens (LIU et al., 2009; CHEN et al., 2013; YEH et al., 2014 ) A exemplo de EPSs microbianos já descritos na literatura tem-se: levana obtida de Zymomonas mobilis, dextranas obtidas de Leuconostoc mesenteroides, xantana obtidas de Xantomonas campestres, gelana obtida de Sphingomonas paucimobilis, pululana obtida de Aureobasidium pullulans, alginate obtida por Pseudomonas aeruginosa e Azotobacter vinelandii e celulose obtida por Gluconacetobacter xylinus, (CARVALHO et al., 2006; ONER, 2013).

A partir de uma nova abordagem a ser tomada com relação a microorganismos endofíticos contaminantes de cultura de tecido vegetal o presente estudo visou avaliar o seu possível potencial biotecnológico. Para esse fim, este trabalho visou a utilização de bactérias endofíticas isoladas a partir de contaminantes de cultura de tecido vegetal associados à cana-de-açúcar para a produção de EPSs.

\section{Obtenção das cepas bacterianas}

\section{MATERIAL E MÉTODOS}

As cepas bacterianas utilizadas neste trabalho foram obtidas a partir da bacterioteca do Laboratório de Microbiologia Ambiental e Biotecnologia do Instituto de Patologia Tropical e Saúde Pública da Universidade Federal de Goiás (LAMAB/IPTSP/UFG). Essas cepas são provenientes de estudos anteriores de isolamento de contaminantes endofíticos, presentes em culturas de tecidos vegetal associados à cana-de-açúcar.

Os isolados bacterianos encontravam-se conservados em caldo $\mathrm{BHI}$ (Brain Heart Infusion) glicerinado $(20 \%)$ em freezer a $-20^{\circ} \mathrm{C}$. Para a recuperação e verificação da viabilidade celular das cepas, essas foram inoculadas em $5,0 \mathrm{~mL}$ de caldo $\mathrm{BHI}$ a $30^{\circ} \mathrm{C}$ por 48 horas. Após as 48 horas foi observado o turvamento do meio de cultura indicando o crescimento celular. Visando a purificação das colônias e confirmação da viabilidade celular, foi utilizada a técnica de esgotamento em ágar $\mathrm{BHI}$ (5 vezes). A pureza das bactérias foi determinada através da visualização de características de cada colônia isolada em placa livre de contaminantes. Para a caracterização e visualização morfológica das cepas, foi efetuada a técnica morfotintorial de coloração de Gram. 
Foi realizada uma triagem das cepas para identificação de potenciais produtores de EPSs, apenas aqueles que em meio caldo BHI em condições estáticas de crescimento produziam um material suspenso de caráter insolúvel, foram consideradas potenciais produtoras de EPSs.

\section{Produção de exopolissacarídeo}

Visando a padronização da produção de EPSs ensaios prévios foram realizados para padronização dessa metodologia. Direcionando a produção para o EPS celulose, foi utilizado o meio de cultivo descrito na literatura por HESTRIN \& SCHRAMM (1954) (20g/l de glucose, $5 \mathrm{~g} / \mathrm{l}$ de extrato de levedura, $5 \mathrm{~g} / \mathrm{l}$ de peptona, $2,7 \mathrm{~g} / \mathrm{l}$ de fosfato de sódio dibásico e 1,15g/l de ácido cítrico, $\mathrm{pH} 5,5 \mathrm{a} \mathrm{6,5).}$

Para fermentação, foi empregado um volume de $25 \mathrm{~mL}$ do meio de cultivo HESTRIN \& SCHRAMM (1954) acrescido uma suspensão de células bacterianas em ágar BHI utilizada como inóculo, sobre agitação a $120 \mathrm{rpm}$ em shaker com temperatura constante de $30^{\circ} \mathrm{C}$. A fermentação procedeu em tempos variados de 24 , 48 e 72 horas.

A precipitação e lavagem dos EPSs foi realizada segundo a metodologia de ALMEIDA et al., (2008) e CARREIRA (2010), com adaptações. Para precipitação dos EPSs, foi adicionado ao meio fermentado um volume de $25 \mathrm{~mL}$ de solução de etanol-acetona na proporção 1:1 (v/v), com consecutiva centrifugação a temperatura de $10^{\circ} \mathrm{C}$ durante 30 minutos com rotação de $4000 \mathrm{rpm}$. Ao final dessa etapa, 0 sobrenadante foi descartado e o pellet foi lavado inicialmente com 2,0 mL de solução de $\mathrm{HCL}$ a $5 \%$ e centrifugado por cinco minutos a $10^{\circ} \mathrm{C}$ com rotação de $4000 \mathrm{rpm}$. Em seguida, o sobrenadante foi novamente descartado e o pellet novamente lavado com uma solução de $\mathrm{NaOH} 5 \%$ com outra centrifugação nas mesmas condições anteriormente descritas. Para neutralização do $\mathrm{pH}$, o pellet formado foi lavado três vezes em água destilada e centrifugado também nas mesmas condições.

Os pellets formados de cada cepa foram então colocados em uma membrana de filtração de éster de celulose com $0,45 \mu \mathrm{m}$ de poro e $47 \mathrm{~mm}$ de diâmetro (Millipore). Em seguida, as membranas foram colocadas em placas de Petri descartáveis em um recipiente com tampa em cujo interior continha esferas de sílica. As placas de Petri com as membranas foram mantidas por três dias, para a secagem total do EPSs produzido.

\section{Determinação do exopolissacarídeo produzido}

Para quantificação dos EPSs produzidos, as membranas de filtração foram pesadas antes e após a produção dos EPSs, com a obtenção do peso de cada massa de EPSs produzido de cada fermentação.

\section{Determinação do crescimento bacteriano}

Após cada produção de EPSs, uma alíquota do meio de cultivo fermentado foi retirada e foi determinada a densidade óptica (DO) por espectrofotometria (BIO RAD - SmartSpec) a $600 \mathrm{~nm}$, utilizando como padrão $1,5 \times 10^{8} \mathrm{cel} / \mathrm{mL}$.

\section{Quantificação de glucose}

A glucose foi quantificada pelo método enzimático da glucose (Kit Glucose Enzimática Líquida Doles $\left.{ }^{\circledR}\right)$ seguindo o protocolo fornecido pelo fabricante. A quantificação da glucose ocorreu em cada etapa de produção de EPSs no meio de cultivo fermentado, com o meio de cultivo HESTRIN \& SCHRAMM (1954) limpo como controle. 


\section{Microscopia eletrônica de varredura}

A visualização dos EPSs foi realizada por meio de microscopia eletrônica de varredura (MEV), onde foram fotomicrografadas os EPSs produzidos e secados em membrana de filtração. Para as análises de MEV as amostras, além da secagem por sílica, também foram submetidas à secagem pelo ponto crítico de $\mathrm{CO}_{2}$ (Autosamdri® 815, séries $A$ ), seguido de recobrimento por deposição de filmes de ouro (Deton Vacuum, Desk V, equipado com o acessório de carbono). A seguir, o material foi encaminhado para o aparelho Jeol JSM - 6610, equipado com EDS, Thermo scientific NSS Spectral Imaging. Essa parte experimental foi realizada no Laboratório Multiusuário de Microscopia de Alta Resolução da Universidade Federal de Goiás (LabMic/UFG).

\section{Análise estatística}

Para realização dos dados estatísticos foi usado o Programa Microsoft Excel versão 2013, para cálculos de média, desvio padrão e correlação de Person.

\section{RESULTADOS E DISCUSSÃO}

$\mathrm{Na}$ triagem inicial, seis isolados (cepas 06, 07, 8B, 09, 11A e 12B) da bacterioteca foram considerados como potenciais produtores de EPSs. Todos produziram material de caráter insolúvel quando crescidos em meio liquido e também foi observada uma característica distinta quando em meio sólido a qual consistia da formação de uma goma, em forma de véu ao redor das colônias, com o odor característico de enxofre (provavelmente referente à via metabólica de produção do EPS) e com uma grande retenção de líquido. Apenas a cepa 09 exibiu a característica de ser seca e friável. Todas as seis cepas bacterianas foram caracterizadas como bastonetes gram-positivos.

TOLEDO (2011) conduziu o isolamento e a identificação molecular de bactérias endofíticas em culturas de micropropagação de cana-de-açúcar, tendo encontrado principalmente os gêneros Alicyclobacillus, Bacillus, Lactobacillus, Leuconostoc, Acidisoma, Acidomonas, Gluconacetobacter, Rhizobium, Achromobacter, Burkhoderia, Herbaspirillum, Ralstonia, Acinetobacter, Enterobacter, Klebsiella, Pantoea, Pseudomonas e Stenotrophomonas. Dentre esses, todos os representantes do filo Firmicutes - Alicyclobacillus, Bacillus, Lactobacillus e Leuconostoc - são conhecidamente produtores de exopolissacarídeos (VU et al., 2009). Será realizada a caracterização molecular com base na amplificação, sequenciamento e análise da região do $16 \mathrm{~S}$ rRNA dos isolados bacterianos para sua completa identificação, contudo pelos resultados da análise morfológica, pode-se sugerir que estes pertençam a algum desses gêneros de bactérias gram-positivas citados acima.

A produção de EPSs foi realizada em três pontos seguidos de tempo de fermentação. Foram avaliados os parâmetros de produção de EPSs em biomassa ( $\mathrm{mg} / 25 \mathrm{~mL}$ de meio de cultivo) e crescimento celular por meio da densidade celular (cel/mL). Também foi realizada uma análise estatística de correlação para avaliar se existe alguma associação entre os dois parâmetros analisados. Os resultados estão exibidos na Tabela 1. 
TABELA 1: Parâmetros de produção de exopolissacarídeos pelas cepas bacterianas.

\begin{tabular}{|c|c|c|c|c|c|c|c|c|c|}
\hline \multirow[b]{3}{*}{ Cepas } & \multicolumn{4}{|c|}{$\begin{array}{c}\text { Biomassa de EPSs produzido } \\
(\mathrm{mg} / 25 \mathrm{~mL})\end{array}$} & \multicolumn{4}{|c|}{ Densidade bacteriana (cel/mL) } & \multirow[t]{3}{*}{$\begin{array}{l}\text { Correlação } \\
\text { de Person }\end{array}$} \\
\hline & \multicolumn{3}{|c|}{ Tempo de fermentação } & \multirow[t]{2}{*}{ Média \pm DP } & \multicolumn{3}{|c|}{ Tempo de fermentação } & \multirow[t]{2}{*}{ Média \pm DP } & \\
\hline & $24 \mathrm{~h}$ & $48 \mathrm{~h}$ & $72 \mathrm{~h}$ & & $24 \mathrm{~h}$ & $48 h$ & $72 \mathrm{~h}$ & & \\
\hline 06 & 0,99 & 17,49 & 9,49 & $9,32 \pm 8,25$ & $1,97 \times 10^{7}$ & $2,60 \times 10^{8}$ & $3,26 \times 10^{8}$ & $\begin{array}{c}2,02 \times 10^{8} \pm \\
1,6 \times 10^{8}\end{array}$ & 0,76 \\
\hline 08B & 1,59 & 10,29 & 12,00 & $7,96 \pm 5,58$ & $1,85 \times 10^{7}$ & $2,71 \times 10^{8}$ & $5,71 \times 10^{8}$ & $\begin{array}{c}2,87 \times 10^{8} \pm \\
2,76 \times 10^{8}\end{array}$ & 0,91 \\
\hline 09 & 7,39 & 13,19 & 10,49 & $10,36 \pm 2,90$ & $2,05 \times 10^{7}$ & $1,67 \times 10^{8}$ & $3,53 \times 10^{8}$ & $\begin{array}{c}1,80 \times 10^{8} \pm \\
1,67 \times 10^{8}\end{array}$ & 0,47 \\
\hline 12B & 7,17 & 7,17 & 10,39 & $8,24 \pm 1,86$ & $6,65 \times 10^{7}$ & $1,03 \times 10^{8}$ & $3,69 \times 10^{8}$ & $\begin{array}{c}1,79 \times 10^{8} \pm \\
1,65 \times 10^{8}\end{array}$ & 0,99 \\
\hline
\end{tabular}

*DP: desvio-padrão; *: entre as variáveis biomassa de EPSs produzidos e densidade bacteriana. 
De modo amplo, inicialmente ocorreu um crescimento da produção de biomassa seca de EPSs nos intervalos de fermentação analisados. Após 48 horas, ocorreu uma queda do crescimento da biomassa de EPSs nos isolados 06, 09 e 11A. Já para os isolados $07,8 \mathrm{~B}$ e $12 \mathrm{~B}$ esse crescimento prosseguiu, entretanto, este é mais lento quando comparados com o crescimento nos intervalos de 24 e 48 horas. Pode-se observar que a densidade bacteriana nos intervalos de tempo fermentação avaliados a um crescimento ao decorrer do tempo. Pelos valores de médias e desvios padrões tanto biomassa de EPSs quanto a densidade celular, observou-se que existe uma grande variação, entretanto, analisando os dados criticamente, observou-se que o melhor tempo de fermentação e produção de EPSs foi de 48 horas, com as cepas 07 e $11 \mathrm{~A}$ apresentando-se como as melhores produtores de EPSs. A correlação linear entre a biomassa de EPSs e a densidade bacteriana na fermentação foi positiva, porém a cepa 11A possui esta associação linear baixa quando comparada aos outros isolados.

De modo amplo, inicialmente ocorreu um crescimento da produção de biomassa seca de EPSs nos intervalos de fermentação analisados. Após 48 horas, ocorreu uma queda do crescimento da biomassa de EPSs nos isolados 06, 09 e $11 \mathrm{~A}$. Já para os isolados $07,8 \mathrm{~B}$ e $12 \mathrm{~B}$ esse crescimento prosseguiu, entretanto, este é mais lento quando comparados com o crescimento nos intervalos de 24 e 48 horas. Pode-se observar que a densidade bacteriana nos intervalos de tempo fermentação avaliados a um crescimento ao decorrer do tempo. Pelos valores de médias e desvios padrões tanto biomassa de EPSs quanto a densidade celular, observou-se que existe uma grande variação, entretanto, analisando os dados criticamente, observou-se que o melhor tempo de fermentação e produção de EPSs foi de 48 horas, com as cepas 07 e $11 \mathrm{~A}$ apresentando-se como as melhores produtoras de EPSs. A correlação linear entre a biomassa de EPSs e a densidade bacteriana na fermentação foi positiva, porém a cepa 11A possui esta associação linear baixa quando comparada aos outros isolados.

Geralmente a produção de um exopolissacarídeo por um micro-organismo é induzida pela limitação de um nutriente essencial, excetuando-se o carbono ou outra fonte de energia. No decorrer do processo de fermentação, há a conversão da fonte de carbono em bipolímero pela célula microbiana sob certos parâmetros fixos (SOUZA \& GARCIA-CRUZ, 2004; ERNANDES \& CRUZ, 2005). Além disso, é importante salientar que a produção de EPSs pode estar associada à qualquer fase do crescimento microbiano e, na maioria dos estudos, existe a tentativa de estabelecimento de uma correlação entre o crescimento microbiano e a geração do polímero.

Geralmente é verificado um aumento de produção concomitante com as fases de crescimento inicial e exponencial, uma taxa constante e declínio na fase estacionária, a qual pode estar associada com a síntese de enzimas que degradam o EPS pelo próprio micro-organismo (MORE et al., 2014). Com base na correlação linear positiva observada entre os parâmetros biomassa de EPSs e densidade celular microbiana para os crescentes intervalos de tempo de fermentação, pode-se confirmar que a geração do polímero pelas bactérias endofíticas está relacionada justamente às etapas exponencial e estacionária de crescimento. Todavia, outras variáveis, como diferentes meios e condições de cultivo fermentativo, devem ser avaliadas para obtenção de um melhor panorama da biossíntese do biopolímero, particularmente para os melhores produtores, visando compreender e otimizar o processo, por exemplo, para o isolado 11A que, apesar de se mostrar como um bom 
produtor nessa triagem, não foi verificada uma correlação linear alta entre os parâmetros.

Outro parâmetro analisado foi o consumo de glucose, fonte de carbono empregada na fermentação. Os dados deste resultado se encontram na Tabela 2. 0 meio de cultura sem inóculo (meio de cultura limpo, autoclavado) foi utilizado como padrão para comparação, obtendo nele a concentração de $943,248 \mathrm{mg} / 100 \mathrm{~mL}$ de glucose.

TABELA 2: Quantificação de glucose, produção de EPSs (mg/100mL)

\begin{tabular}{llcl}
\hline Cepas & \multicolumn{3}{c}{ Tempo de fermentação } \\
\cline { 2 - 4 } & 24 horas & 48 horas & 72 horas \\
\hline 06 & 948,648 & 931,419 & 973,648 \\
07 & 947,297 & 899,662 & 959,797 \\
08B & 936,486 & 933,784 & 936,486 \\
09 & 936,824 & 945,608 & 944,594 \\
11A & 930,405 & 841,554 & 926,689 \\
12B & 956,756 & 954,054 & 953,716 \\
\hline
\end{tabular}

Pode ser notado que, para alguns isolados, a dosagem de glucose aumentou, comparada com a concentração padrão, e não diminui. Este resultado pode ter ocorrido devido ao fato de que o meio isolado era característico para produção de celulose bacteriana e, supondo que o EPSs produzido seja de fato celulose, pode ter ocorrido erro de reação cruzada, em conseqüência desse polissacarídeo ser composto por monômeros de glucose. Outra possível razão é que as cepas podem estar produzindo glucose e exportando para fora da célula. Com esta interferência nos resultados, não se pode calcular o fator de conversão de substrato em produto, EPSs.

Uma outra explicação, e a mais provável é a síntese de polissacarases e outras liases degradativas de EPS que seriam produzidas já na fase exponencial e, principalmente na fase estacionária do crescimento microbiano e, assim, o próprio biopolímero estaria sendo degradado em suas unidades monoméricas. É de fundamental importância a caracterização estrutural do polímero para entender exatamente tais resultados obtidos na dosagem de glucose durante o processo fermentativo e também na adaptação da constituição do meio de cultivo empregado para otimização da produção bacteriana do EPS.

Caso os isolados endofíticos pertençam ao mesmo gênero, os resultados obtidos no estudo já seriam esperados. FERNANDES JÚNIOR et al., (2010) relatam que é comum encontrar produção variável de EPSs em bactérias do mesmo gênero cultivadas sob condições idênticas. Deve ser considerado também que, de modo amplo, a quantidade e a composição do biopolímero é altamente variável dependendo do gênero e espécie da bactéria (MU'MINAH et al., 2015).

A visualização dos EPSs foi realizada por meio de $\mathrm{MEV}$, com as fotomicrografias abaixo na Figura 1. Pode ser visualizado que os EPSs permaneceram associados aos bastonetes gram-positivos, evidenciando que na etapa de precipitação os micro-organismos não foram separados dos EPSs. Pela microscopia também observou-se que as cepas 06, 09 e 12B produzem os EPSs com a morfologia parecida, as cepas 07 e $11 \mathrm{~A}$ são as que apresentam maior produção visualmente de EPSs na microscopia e a cepa 08B possui um tipo de EPSs com características morfologicamente diferentes das demais. 
Uma opção para melhor análise morfológica por microscopia eletrônica seria um processamento do polímero anteriormente à etapa de secagem de tal forma que ocorresse uma separação das células microbianas do exopolissacarídeo. Esse processamento até mesmo auxiliaria na identificação do biopolímero, como, por exemplo, visualizar as microfibrilas de celulose, no caso o provável EPS que se acredita que os isolados em questão produzam. Uma alternativa seria o congelamento durante o preparo das amostras para a microscopia eletrônica, após obviamente etapas que visassem a desagregação das células bacterianas do polímero (CASTRO et al., 2012). Todavia, esse processamento pode ser bem complexo dependendo da natureza e da síntese do EPS pelo isolado, uma vez que o polímero pode estar muito associado à parede celular bacteriana. Para isolados endofíticos, isso é especialmente verificado, já que a geração do polímero é um dos fatores essenciais para a formação de biofilme e colonização inicial no vegetal hospedeiro (MENESES et al., 2011).

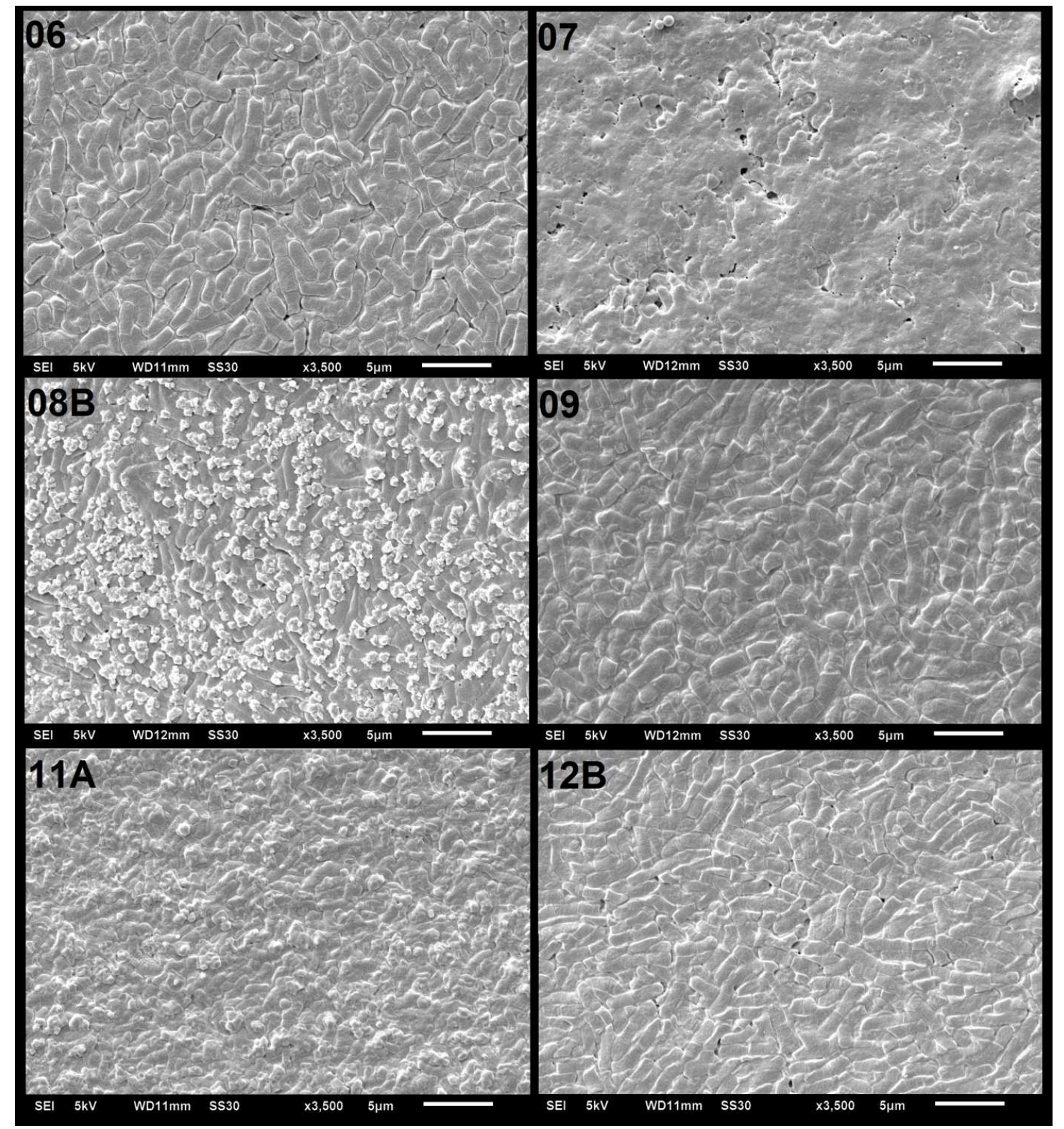

FIGURA 1: Fotomicrografia de MEV dos exopolissacarídeos associados aos isolados bacterianos endofíticos.

Fonte: autores 
Recentemente, HECTOR et al., (2015) isolaram bactérias do bagaço e resíduos industriais de cana-de-açúcar e avaliaram a produção de EPS pelas mesmas, uma vez que a geração do polímero pode ser um problema grave no processamento industrial da cana-de-açúcar. Os autores observaram uma ampla produção de EPS para os 25 isolados pertencentes aos gêneros Weisella, Lactobacillus e Salmonella os quais empregavam crucialmente glucose como fonte de carbono para a síntese. Contudo, a produção do EPS variava de acordo com a fonte de açúcar empregada no meio de produção, sendo essa essencialmente dependente de sacarose, o que apontou inclusive em um melhor tratamento enzimático para evitar o prejuízo da formação do EPS bacteriano no setor industrial.

\section{CONCLUSÃO}

Todas as seis amostras bacterianas gram-positivas isoladas de culturas de micropropagação vegetal de cana-de-açúcar exibiram em diferentes proporções a produção de EPS em cultivo meio HESTRIN \& SCHRAMM (1954), com destaque aos isolados 07 e 11A. A dosagem de glucose para os diferentes tempos de fermentação evidenciou o aumento da concentração do monossacarídeo para alguns isolados, o que pode ser justificado ao crescimento microbiano e a provável natureza celulósica do EPS. A geração do polissacarídeo foi confirmada pela análise morfológica por MEV. Estudos estão sendo executados para identificação molecular dos isolados bacterinos endofíticos e para a caracterização estrutural do biopolímero por métodos físico-químicos e enzimáticos de modo a contribuir na adaptação do processo de fermentação e, assim, uma adequada obtenção de EPS, já visando suas múltiplas aplicações biotecnológicas.

\section{REFERÊNCIAS}

ALMEIDA, D. M.; WOSIACKI G.; SANTOS JUNIOR S; MADALOZZO, E. S; ZANLOREZI, M. M. Crescimento do Acetobacter xylium (ATCC23769) e a produção de celulose bacteriana. Revista Brasileira de Tecnologia Agroindustrial, v. 2, p. 95-103, 2008.2 Disponível em: <https://periodicos.utfpr.edu.br/rbta/article/view/274/242>. doi: 10.3895/S198136862008000100009

ARUN, J.; SELVAKUMAR, S.; SATHISHKUMAR, R.; MOOVENDHAN, M.; ANANTHAN, G.; MARUTHIAH, T.; PALAVESAM, A. In vitro antioxidant activities of an exopolysaccharide from a salt pan bacterium Halolactibacillus miurensis. Carbohydrate Polymers, v.155, p. 400-406, 2017. Disponível em: <http://dx.doi.org/10.1016/j.carbpol.2016.08.085>. doi: 10.1016/j.carbpol.2016.08.085

CARREIRA, P. M. C. Produção de celulose bacteriana a partir de resíduos industriais. Dissertação (Mestrado em Materiais Derivados de Recursos Renováveis), Universidade de Aveiro, Aveiro, 2010. Disponível em: <http://ria.ua.pt/bitstream/10773/3981/1/tese\%20final.pdf>.

CARVALHO W.; CANILHA L.; SILVA D. D. V.; MANCILHA I. M. Aditivos alimentares produzidos por via fermentativa parte3: polissacarídeos e enzimas. Revista

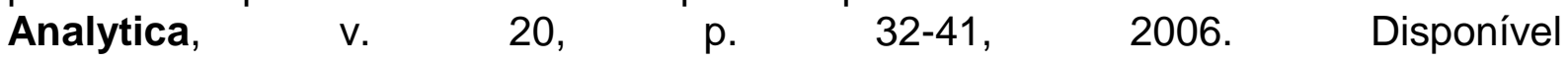
em:<http://w.revistaanalytica.com.br/ed_anteriores/20/art04.pdf>. 
CASTELLANE, T. C. L.; LEMOS, M. V. F.; DE MACEDO LEMOS, E. G. Evaluation of the biotechnological potential of Rhizobium tropici strains for exopolysaccharide production. Carbohydrate Polymers, v. 111, p. 191-197, 2014. Disponível em: <http://dx.doi.org/10.1016/j.carbpol.2014.04.0660>. 10.1016/j.carbpol.2014.04.0660

CASTRO, C.; ZULUAGA, R.; ÁlVAREZ, C.; PUTAUX, J-L.; CARO, G.; ROJAS, O. J.; MONDRAGON, I., GAÑÁN, P. Bacterial cellulose produced by a new acidresistant strain of Gluconacetobacter genus. Carbohydrate Polymers, v. 89, n. 4, p. 1033-1037, 2012. Disponível em: <http://dx.doi.org/10.1016/j.carbpol.2012.03.045>. doi: 10.1016/j.carbpol.2012.03.045

CHEN, Y. T.; YUAN, Q.; SHAN, L. T.; LIN, M. A.; CHENG, D. Q.; LI, C. Y. Antitumor activity of bacterial exopolysaccharides from the endophyte Bacillus amyloliquefaciens sp. isolated from Ophiopogon japonicus. Oncology letters, v. 5, n. 6, p. 1787-1792, 2013. Disponível em: <http://dx.doi.org/10.3892/ol.2013.1284>. doi: $10.3892 / 01.2013 .1284$

ERNANDES, F. M. P.; CRUZ, C. H. G. Bacterial Levan: tecnological aspects, characteristics and production. Semina: Ciências Agrárias, v. 26, n. 1, p. 72-82, 2005. Disponível em: <http://dx.doi.org/10.5433/1679-0359.2005v26n1p71>. doi: 10.5433/1679-0359.2005v26n1p71

FERNANDES JÚNIOR, P. I.; ALMEIDA, J. P. S., PASSOS, S. R., OLIVEIRA, P. J., RUMJANEK, N. G.; XAVIER, G. R. Production and rheological behavior of exopolysaccharide synthesized by pigeonpea rhizobia isolates. Pesquisa Agropecuária Brasileira, v. 45, n. 12, p. 1465-1471, 2010. Disponível em: < http://dx.doi.org/10.1590/S0100-204X2010001200018>. doi: 10.1590/S0100204X2010001200018

HECTOR, S.; WILLARD, K.; BAUER, R.; MULAKO, I.; SLABBERT, E.; KOSSMANN, J.; GEORGE, G. M. Diverse exopolysaccharide producing bacteria isolated from milled sugarcane: implications for cane spoilage and sucrose yield. Plos One, v. 10, n. 12, p. $\quad$ e0145487, $2015 . \quad$ Disponível em: <http://dx.doi.org/10.1371/journal.pone.0145487>. 10.1371/journal.pone.0145487

HESTRIN, S.; SCHRAMM, M. Synthesis of cellulose by Acetobacter xylinum preparation of freeze dried cells capable of polymerizing glucose to cellulose. Biochem, v. 58, p. 345-352, 1954. Disponível em: <https://www.ncbi.nlm.nih.gov/pmc/articles/PMC1269899/>.

LIU, J.; LUO, J.; YE, H.; SUN, Y.; LU, Z.; ZENG, X. Production, characterization and antioxidant activities in vitro of exopolysaccharides from endophytic bacterium Paenibacillus polymyxa EJS-3. Carbohydrate Polymers, v. 78, n. 2, p. 275-281, 2009. Disponível em: <http://dx.doi.org/10.1016/j.carbpol.2009.03.046>. doi: 10.1016/j.carbpol.2009.03.046

LIU, J.; LUO, J.; YE, H.; ZENG, X. Preparation, antioxidant and antitumor activities in vitro of different derivatives of levan from endophytic bacterium Paenibacillus 
polymyxa EJS-3. Food and Chemical Toxicology, v. 50, n. 3, p. 767-772, 2012. Disponível em:

em:

MAHAPATRA, S.; BANERJEE, D. Structural elucidation and bioactivity of a novel exopolysaccharide from endophytic Fusarium solani SD5. Carbohydrate polymers, v. 90 , n. 1 , p. 683-689, 2012. Disponível em: $<$ http://dx.doi.org/10.1016/j.carbpol.2012.05.097>. 10.1016/j.carbpol.2012.05.097

MENESES, C. H. S. G.; ROUWS, L. F. M.; SIMÕES-ARAÚJO, J. L., VIDAL, M. S.; BALDANI, J. L. Exopolysaccharide production is required for biofilm formation and plant colonization by the nitrogen-fixing endophyte Gluconacetobacter diazotrophicus. Molecular Plant-Microbe Interaction, v. 24, n. 12, p. 1448-1458, 2011. Disponível em: <http://dx.doi.org/10.1094/MPMI-05-11-0127>. doi: 10.1094/MPMI-05-11-0127

MORE, T. T.; YADAV, J. S. S.; YAN, S.; TYAGI, R. D.; SURAMPALLI, R. Y. Extracellular polymeric substances of bacteria and their potential environmental applications. Journal of Environmental Managment, v. 144, p. 1-25, 2014. Disponível em: <http://dx.doi.org/10.1016/j.jenvman.2014.05.010>. doi: 10.1016/j.jenvman.2014.05.01

MU'MINAH, BAHARUDDIN, SUBAIR, H., FAHRUDDIN. Isolation and screening bacterial exopolysaccharide (EPS) from potato rhizosphere in highland and the potential as a producer Indole Acetic Acid (IAA). Procedia Food Science, v. 3, p. 7481, 2015. Disponível em: <http://dx.doi.org/10.1016/j.profoo.2015.01.007>. doi: 10.1016/j.profoo.2015.01.007

ONER, E. T. Microbial production of extracellular polysaccharides from biomass. Green Energy and Technology, p. 35-56, 2013. Disponível em: <http://dx.doi.org/10.1007/978-3-642-32735-3_2>. doi: 10.1007/978-3-642-327353_2

ORLANDELLI, R. C.; VASCONCELOS, A. F. D.; AZEVEDO, J. L.; DA SILVA, M. D. L. C.; PAMPHILE, J. A. Screening of endophytic sources of exopolysaccharides: Preliminary characterization of crude exopolysaccharide produced by submerged culture of Diaporthe sp. JF766998 under different cultivation time. Biochimie Open, v. 2, p. 33-40, 2016. Disponível em: <http://dx.doi.org/10.1016/j.biopen.2016.02.003>. doi: 10.1016/j.biopen.2016.02.003

POLESI, N. P. E. Microrganismos endofíticos e a cultura de tecidos vegetais: quebrando paradigmas. Revista Brasileira de Biociências, v. 9, p. 533-541, 2011. Disponível em: <http://www.ufrgs.br/seerbio/ojs/index.php/rbb/article/view/1914>.

SARDARI, R. R.; KULCINSKAJA, E., RON, E. Y., BJÖRNSDÓTTIR, S.; FRIĐJÓNSSON, Ó. H.; HREGGVIĐSSON, G. Ó.; KARLSSON, E. N. Evaluation of the production of exopolysaccharides by two strains of the thermophilic bacterium Rhodothermus marinus. Carbohydrate Polymers, v. 156, p. 1-8, 2017. Disponível 
em <http://dx.doi.org/10.1016/j.carbpol.2016.08.062>.

doi:

10.1016/j.carbpol.2016.08.062

SINGH, R. P.; SHUKLA, M. K.; MISHRA, A.; KUMARI, P.; REDDY, C. R. K.; JHA, B. Isolation and characterization of exopolysaccharides from seaweed associated bacteria Bacillus licheniformis. Carbohydrate polymers, v. 84, n. 3, p. 1019-1026, 2011. Disponível em: <http://dx.doi.org/10.1016/j.carbpol.2010.12.061>. doi: 10.1016/j.carbpol.2010.12.061

SOUZA, D. M.; GARCIA-CRUZ, C. Fermentative production of exocellular polysaccharides by bacteria. Semina: Ciências Agrárias, v. 25, n. 4, p. 331-340, 2004. Disponível em: <http://dx.doi.org/10.5433/1679-0359.2004v25n4p331>. doi: 10.5433/1679-0359.2004v25n4p331

TOLEDO, C. P. Identificação e controle de microrganismos contaminantes no processo de micropropagação de cana-de-açúcar. 2011. 73 f. Dissertação (Mestrado em Microbiologia Agrícola). Escola Superior de Agricultura "Luiz de Queiroz", Universidade de São Paulo, Piracicaba, 2011.

VU, B.; CHEN, M.; CRAWFORD, R. J.; IVANOVA, E. P. Bacterial extracellular polysaccharides involved in biofilm formation. Molecules, v. 14, n. 7, p. 2535-2554, 2009. Disponível em: <http://dx.doi.org/10.3390/molecules14072535>. doi: 10.3390/molecules 14072535

YEH, C. W.; ZANG, C. Z.; LIN, C. C.; KAN, S. C.; CHANG, W. F.; SHIEH, C. J.; LIU, Y. C. Quantitative and morphologic analysis on exopolysaccharide and biomass production from a truffle endophytic fungus Hypocreales sp. NCHU01. Journal of the Taiwan Institute of Chemical Engineers, v. 45, n. 1, p. 108-114, 2014. Disponível em: <http://dx.doi.org/10.1016/j.jtice.2013.09.020>. doi: 10.1016/j.jtice.2013.09.020 